\title{
Modeling of Deposition Process of Particulate Organic Matter (POM) with Sand on Vegetated Area in a River
}

\author{
Makiko Obana, Ho-Seong Jeon, Tetsuro Tsujimoto \\ Department of Civil Engineering, Nagoya University, Nagoya, Japan \\ Email: mobana@civil.nagoya-u.ac.jp
}

Received 22 August 2014; revised 16 September 2014; accepted 5 October 2014

Copyright (C) 2014 by authors and Scientific Research Publishing Inc.

This work is licensed under the Creative Commons Attribution International License (CC BY). http://creativecommons.org/licenses/by/4.0/

(c) (i) 0 pen Access

\section{Abstract}

The transport and deposition of particulate organic matter (POM) in river streams has recently received much attention as one of important ecological processes in rivers. We focused on interacted behaviors of sand particles in bed load and POM in vegetated area on sand bars. The purpose of this study is to clarify the characteristics of deposition of POM with bed load on sandbars with the riparian vegetation. A basic experiment on POM transport and deposition with vegetation is conducted in a laboratory flume. It demonstrates that several issues still remain to be future investigated. In particular, the shear due to the bed roughness in the vegetated area and the transport and deposition process of sand particles and POM are required to be described by the proper modeling which will be introduced into a simulation model of various fluvial processes. The main results of this study are that ripples are formed by bed load in riparian vegetation and POM deposition is promoted by ripple behavior. Based on these results, the POM deposition with ripples in vegetated area is described by a conceptual model which will affect various aspects in ecosystem management based on fluvial processes.

\section{Keywords}

Modeling, Deposition Process, Particulate Organic Matter (POM), Sand, Vegetated Area

\section{Introduction}

River landscapes are characterized by an interrelating system of flow, sediment transport, morphology and vegetation. It is known that particulate organic matter (POM) with sand particles in bed load and suspended load transported by flood are captured and deposited on sandbar with riparian vegetation. Capture of POM there must 
be significant in ecosystem (Vannote et al. [1], Cummins [2]) and it is important to understand how POM drifts are different from sediment behavior in flow over the vegetated area, because it reversely influences the vegetation productivity and supports the diversity through riverine bio-geochemical processes. The purpose of this study is to clarify the deposition mechanism of POM in consideration of the influence of sediment transport in the riparian vegetation, and to develop the model of POM behavior based on the deposition mechanism. Thus, field observation and laboratory experiment were conducted, and then a modeling necessary in numerical calculation was also conducted.

\section{Characteristics of POM Based on Field Observation}

An investigation was conducted on the Yahagi River (Chubu region, Japan) during normal flow stage. To evaluate the deposition characteristics of various POM with sand on sand-bar with riparian vegetation in a field, we selected a conspicuous island sandbar covered with vegetation. The longitudinal length of sandbar was around $300 \mathrm{~m}$, the cross sectional length was around $100 \mathrm{~m}$ and the average bed slope was $1 / 150$. The bed was composed mainly cobbles and boulders. An herbaceous plant occupied the whole sandbar.

Deposition characteristics of POM with sand particles was estimated by measuring the topography of sandbar and the thickness of sediment deposition layer, observing the spatial distribution of vegetation, and analyzing the grain size distribution of deposited sediments and the quantity of POM contained the deposited sediments. The thickness of deposition layer was measured as the height from the top of basement rock to the top of fine sand layer by using a soil auger at 15 locations in the target sandbar (see Figure 1).

POM content ratio to the total samples included in the sediment was distributed from $0.5 \%$ to $1.5 \%$ at each pointthrough longitudinal direction of sandbar. In addition, specific gravity of POM was observed in a laboratory. POM is classified into CPOM and FPOM according to their sizes. The criterion is $1 \mathrm{~mm}$. We here focused on POM finer, which have less than $5 \mathrm{~mm}$ of particle diameter such as vegetation seeds and litters. Figure 2 shows that the specific weight is distributed from 1.02 to 1.26 for POM while it is around 2.65 for sand. The movement of POM in settling process is completely different from sediment. Sediment was settled rapidly in a group however POM moved flutteringly and settled slowly from top to the bottom of water. It is clear that the settling process of sediment and POM is differed even if they have same diameter.

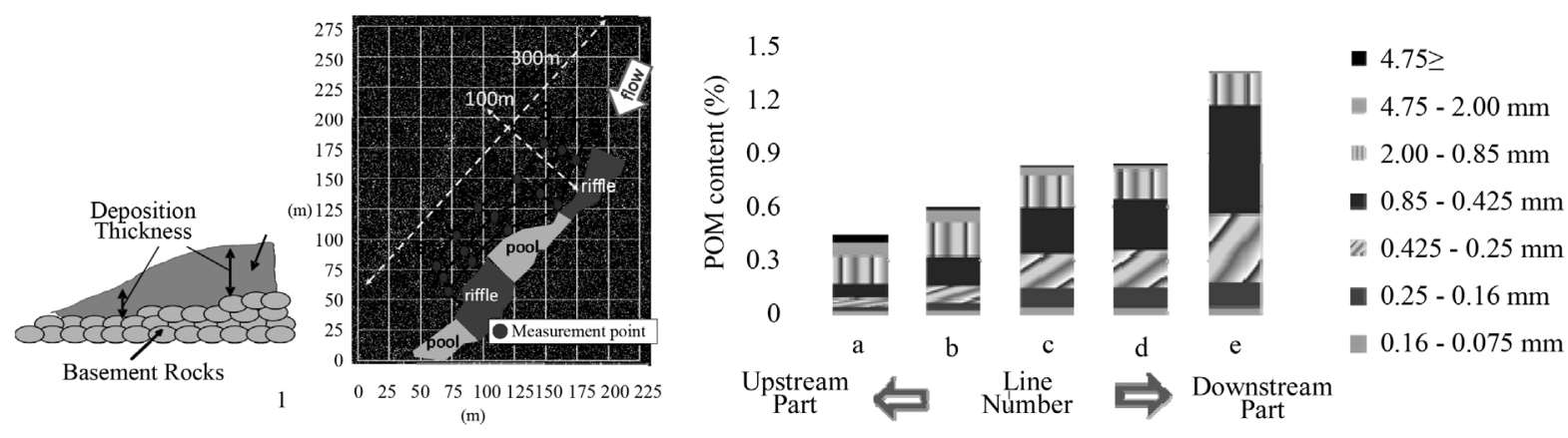

Figure 1. Site location and spatial distribution of POM content ratio according to grain size.
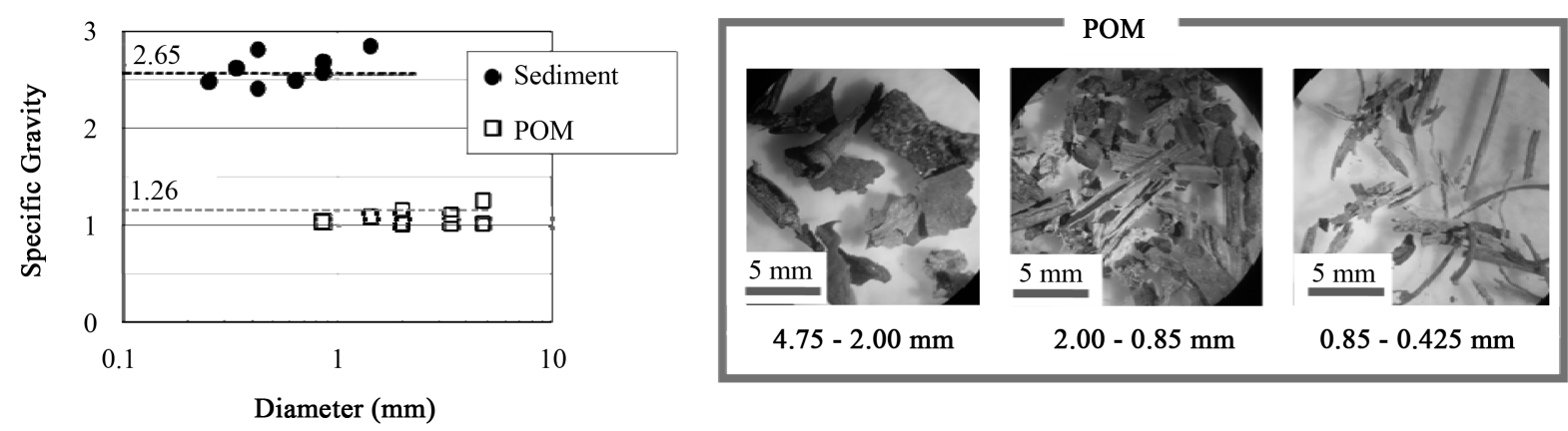

Figure 2. Measurement of specific weight of POM. 


\section{Deposition Process of POM Transported with Sand}

\subsection{Flume Experiment}

Flume experiment was conducted to understand the deposition mechanism of POM, especially CPOM such as vegetation seeds, litters was selected as our target in this study. In the laboratory, a model vegetation made by a group of cylinders made of bamboo arranged in staggered pattern $\left(D=0.25 \mathrm{~mm}, \lambda=0.25 \mathrm{~cm}^{2}\right)$ was set in the interval of $5 \mathrm{~m}$ in a flume $20 \mathrm{~m}$ long and $0.5 \mathrm{~m}$ wide with the constant slope as shown in Figure 3 . The bed was rigid.

Firstly, the flow measurements ( $U$ and $h$ ) were conducted along the centerline of the flume (Obana et al. [3]). Shear velocity $\left(u_{*}\right)$ is also important factor for an analysis of sediment transport. The form drag is predominant and velocity profile is uniform along the depth in flow with non-submerged vegetation sonly except the thin layer near the bed where the boundary layer is developed to bring a shear flow. Thus, after measuring the velocity near the bed with and without vegetated area respectively, shear velocity of vegetated area $\left(u_{* v}\right)$ was deduced based on the assumption under the assumption of the similarity in the ratio of the velocity near the bed $\left(u_{b}\right)$ to the shear velocity between with and without vegetated area (see Table 1). In this table, numerical subscripts 0 and $v$ of shear velocity $u_{*}$, velocity near the bed $u_{b}$, indicates a value of non-vegetated area and vegetated area respectively. The result of this method is confirmed with the theoretical discussion on bed roughness boundary layer (Jeon et al. [4]).

Then, the condition of sand and coarse POM (CPOM) was selected as shown in Figure 4 where $d$ = diameter , $\sigma, \rho=$ mass density of sand and water. The presumed amounts of them were fed at $1 \mathrm{~m}$ upstream of the vegetated area with constant volume along the width. As for CPOM model, we selected PVC (polyvinyl chloride) controlled the specific weight ( $d=0.15 \mathrm{~cm}, \sigma / \rho=1.26$ ). Each supplied sand and POM rate was $0.047 \mathrm{~cm}^{2} / \mathrm{s}$ and $0.06 \mathrm{~cm}^{2}$. At 20 minutes after sediment supply, water is stopped and then deposition of sand and POM in the vegetation area was measured along the centerline in the vegetated zone. Two kinds of experimental cases were run to observe respective fluvial processes of sand and POM. In Case-1, only sand was supplied, while in Case-2 both sand and CPOM were supplied. Movement condition of respective sand and CPOM is changed with/without vegetation; however, they were transported as bed load under this hydraulic condition.

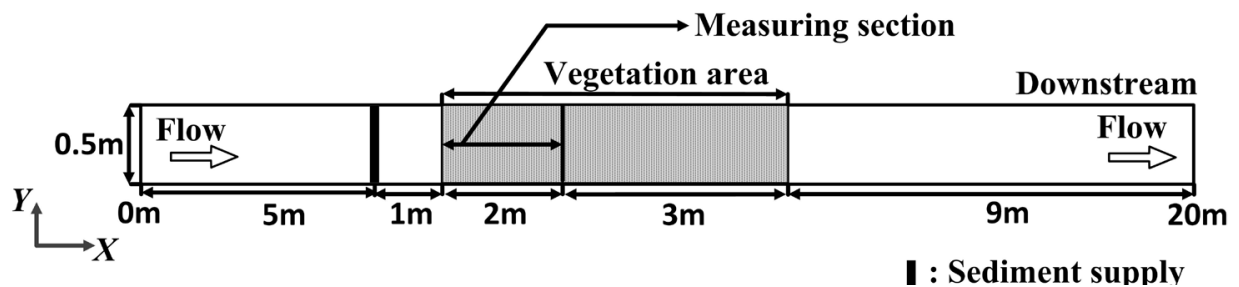

Figure 3. Plan view of experimental channel.

\begin{tabular}{lrrr}
\hline & $\mathrm{d}_{50}(\mathrm{~cm})$ & \multicolumn{1}{c}{$\sigma / \rho$} & $\mathrm{W}_{0}(\mathrm{~cm} / \mathrm{g})$ \\
\hline Sand & 0.025 & 2.65 & 3.13 \\
CPOM (using PVC) & 0.15 & 1.26 & 5.5 \\
\hline
\end{tabular}

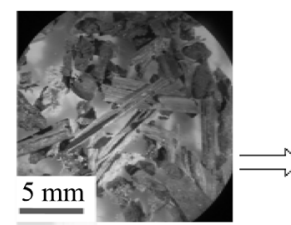

CPOM

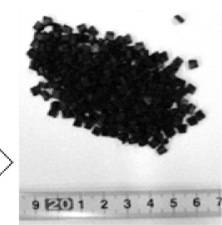

Model CPOM (PVC)

Figure 4. Detail of each experimental sample.

Table 1. Experimental condition.

\begin{tabular}{cccccccc}
\hline $\mathrm{Q}$ & $I_{b}$ & $I_{f}$ & $h_{0}$ & $u_{* 0}$ & $u_{* v}$ & $u_{b 0}$ & $u_{b v}$ \\
\hline$\left(\mathrm{cm}^{3} / \mathrm{s}\right)$ & & & $(\mathrm{cm})$ & $(\mathrm{cm} / \mathrm{s})$ & $(\mathrm{cm} / \mathrm{s})$ & $(\mathrm{cm} / \mathrm{s})$ & $(\mathrm{cm} / \mathrm{s})$ \\
6940 & $1 / 150$ & $1 / 185$ & 3.5 & 4.3 & 2.3 & 14.0 & 7.4 \\
\hline
\end{tabular}




\subsection{Deposition Process of POM Transported with Sand}

Figure 5 shows comparison of deposition thickness of sand and CPOM between Case- 1 and Case- 2 at 1200 seconds after the experiment starts. We observed that sand deposition was occurred even upstream of the beginning of vegetation area in both of cases, and sand was deposited into wavelike fashion along to longitudinal direction. It was judged "ripples" by the figure in the book of Yalin (1977, [5]) which are prepared by overlaying the formation area of ripples and dunes on Shields diagram. Ripples were formed by sediment transport and propagated to downstream with time progress. In contrast, CPOM had never deposited when it was transported by itself in vegetated area. However it was captured and deposited with the progress of ripples due to the both of interactions. The $77 \%$ of all CPOM supply was deposited in vegetated area with sand deposition.

The CPOM deposition mechanism with sand is as follows; 1) firstly fine sand forms ripples; 2) CPOM is deposited behind the crest of ripple, and then, fine sand is deposited and covered on CPOM deposition; 3) finally new CPOM is coming and deposited behind shifted crest of ripple. These steps are then repeated. In Figure 5, we can confirm that CPOM deposition is increasing and propagating with the development of ripples. CPOM deposition amount was measured at representative point in vegetated area as shown in Table 2. By measuring each parameter of ripples at measuring section $(x=30-60 \mathrm{~cm})$, the averaged wave length of ripple was about $9-10 \mathrm{~cm}(L / d=360-400)$, and wave height was $0.45-0.65 \mathrm{~cm}$. And it was clear that each parameter of Case- 2 was decreased because of CPOM which was reduced the development process of ripples by disturbing sand supply from upstream as shown in Table 3.

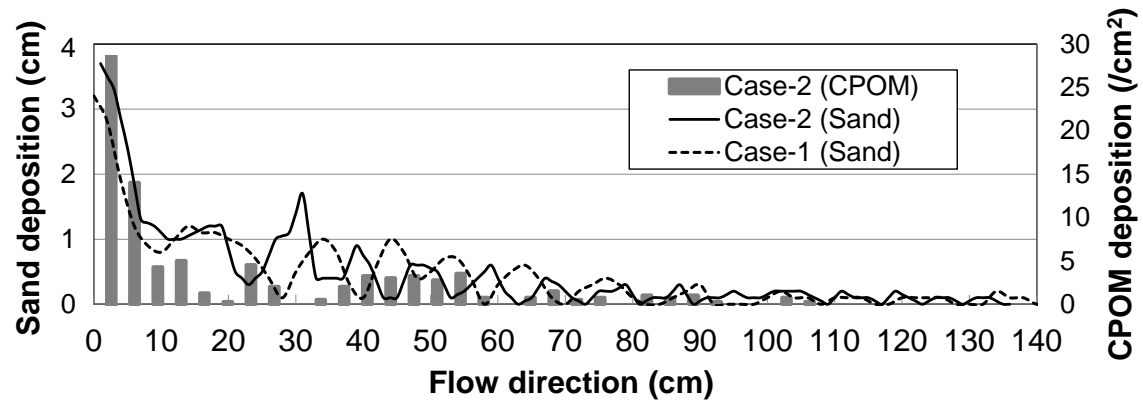

1. CPOM deposition

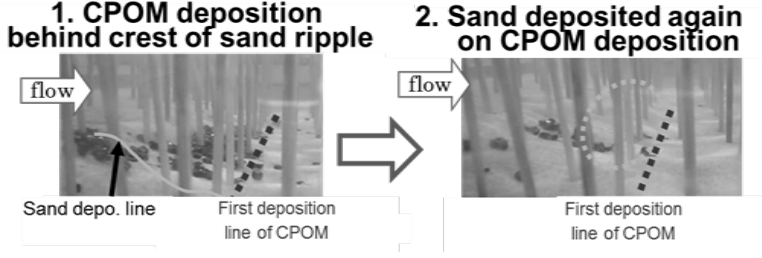

3. New CPOM deposition
behind crest of Sand

Figure 5. Comparison of deposition state between Case-1 (Sand) and Case-2 (Sand + CPOM) at 1200 seconds after the experiment starts.

Table 2. Measured CPOM deposition amount at representative point (Case-2).

\begin{tabular}{cccc}
\hline$x(\mathrm{~cm})$ & $x=40$ & $x=50$ & $x=60$ \\
\hline CPOM deposition amount $\left(/ \mathrm{cm}^{2}\right)$ & 14.25 & 6.50 & 3.00 \\
\hline
\end{tabular}

Table 3. Comparison of wave length, height and propagation velocity of ripple ( $x=40$ - 60 $\mathrm{cm})$.

\begin{tabular}{ccc}
\hline$x=40-60 \mathrm{~cm}$ & Case-1 & Case-2 \\
\hline Wave length: $L(\mathrm{~cm})$ & 10 & 9 \\
Wave height: $H(\mathrm{~cm})$ & 0.65 & 0.45 \\
Propagation velocity: $U_{w}(\mathrm{~cm} / \mathrm{s})$ & 0.021 & 0.019 \\
\hline
\end{tabular}




\section{Modeling of POM Deposition with Ripples}

\subsection{Model Concept}

The flume experiment made it clear that CPOM was captured behind the crest of ripple by separation vortex, then they were deposited and buried in ripples with time progress. Bed load transport can be described by the formula proposed by Ashida \& Michiue [6], and written as follows.

$$
q_{B^{*}} \equiv \frac{q_{B}}{\sqrt{(\sigma / \rho-1) g d^{3}}}=17 \tau_{*}^{3 / 2}\left(1-\frac{\tau_{*_{c}}}{\tau_{*}}\right)\left(1-\sqrt{\frac{\tau_{*_{c}}}{\tau_{*}}}\right)
$$

where $q_{B}, \quad q_{B^{*}}=$ bed load transport rate and its dimensionless expression; $t_{*}=u_{*}^{2} /[(\sigma / \rho-1) g d]=$ Shields number; and $t_{* c}=$ dimensionless critical tractive force. This equation has a dimensionless form, and it may be applied for the various particles which have each different size and relative density $(\sigma / \rho)$.

The Equation (1) is consisted of two kinds of important factors of bed load motion such as sediment number density $v_{g}$ and particle velocity $u_{g}$ as follows (Ashida \& Michiue [6]).

$$
\begin{aligned}
v_{g} d^{2} & =\frac{1}{A_{3} \mu_{R}}\left(\tau_{*}-\tau_{*_{c}}\right) \\
\frac{u_{g}}{u_{*}} & =\phi_{d}\left(1-\sqrt{\frac{\tau_{*_{c}}}{\tau_{*}}}\right)
\end{aligned}
$$

Bed load transport rate has the following relationship with the above two kinds of factors.

$$
q_{B}=v_{g} u_{g} A_{3} d^{3}
$$

where $A_{3}=$ geometrical coefficient of sand; $\mu_{R}=$ friction coefficient of sand $(=0.4) ; \phi_{d}=6.8$ (constant); $t_{*}=$ dimensionless tractive force; and $t_{* c}=$ critical tractive force.

The CPOM particles transported to the lee side of crest of ripple can be described by using the accumulation of supplied number density $v_{g}$, particle velocity $u_{g}$ and capture ratio $\psi$ During the $1^{\text {st }}$ step of time progress $(\Delta t)$, СРOM is captured by the trough of ripple $\left(\psi v_{g} u_{g} \Delta t\right)$, and number of ripple will be increased toward downstream part ( $t_{k}=k L / U_{W}=k \Delta T, k$ : number of ripple) according to the sand deposition. They are buried and deposited along the longitudinal direction $(\Delta x)$ while the ripple migrate one wave length. Thus, CPOM is deposited on a straight line which is connected with the trough of ripple (see Figure 6). And then, temporal change of CPOM deposition amount can be calculated at representative point of vegetated area $\left(x_{j}=x_{0}+j L(j=1 \sim k)\right)$ according to each time step. Accumulated deposition of CPOM (in number) $N_{k j}$ from $x_{1}$ to $x_{j}$ along longitudinal direction according to the temporal change $t_{k}$ could be calculated as shown in Figure 7. When a first ripple is formed $\left(t=t_{1}\right)$, the accumulated amount of CPOM at representative point $\left(x_{1}\right)$ is evaluated by $N_{11}^{*}=\psi\left(N^{*}=N /\left[v_{\mathrm{g}}\left(u_{g} / U_{w}\right)\right]\right)$. As for the second step $(k=2)$, two ripples are formed. Accumulated amount of CPOM $N_{21}^{*}$ is described with sand re-entrainment according to ripplemigration presented as the capture ratio $\psi$ and the residual rate $\beta$ written as follows $\left(N_{21}^{*}=\psi(1+\beta)\right)$. At the same time, $N_{22}^{*}$ in ripple of downstream part is described as $\psi(1-\psi \beta)$.

As above mentioned, we can calculate the temporal and spatial distribution of CPOM deposition with interaction of ripple by using the conceptual model.

\subsection{Simulation of CPOM Deposition and Comparison with Flume Experiment}

Figure 8 shows the comparison between calculated and evaluated results of CPOM deposition by using the conceptual model we proposed. The temporal and spatial change of CPOM deposition amount was calculated by using the proposed model on the basis of assumption of $\psi=0.7, \beta=0.4$. Ripples were formed at 500 seconds intervals $\left(t_{k}=k L / U_{w}=k \Delta T, L=10 \mathrm{~cm}, U_{w}=0.02 \mathrm{~cm} / \mathrm{s}\right)$ based on our experimental results. Bar graph represents the calculated CPOM deposition amount $N^{*}$ for every time during 2000 seconds at representative point of vegetated area $\left(x_{j}=x_{0}+j L(j=1 \sim k), x_{0}=30 \mathrm{~cm}, L=10 \mathrm{~cm}\right)$. The point of CPOM deposition is propagated in the downstream direction with the migration of ripples according to time progress. And CPOM 


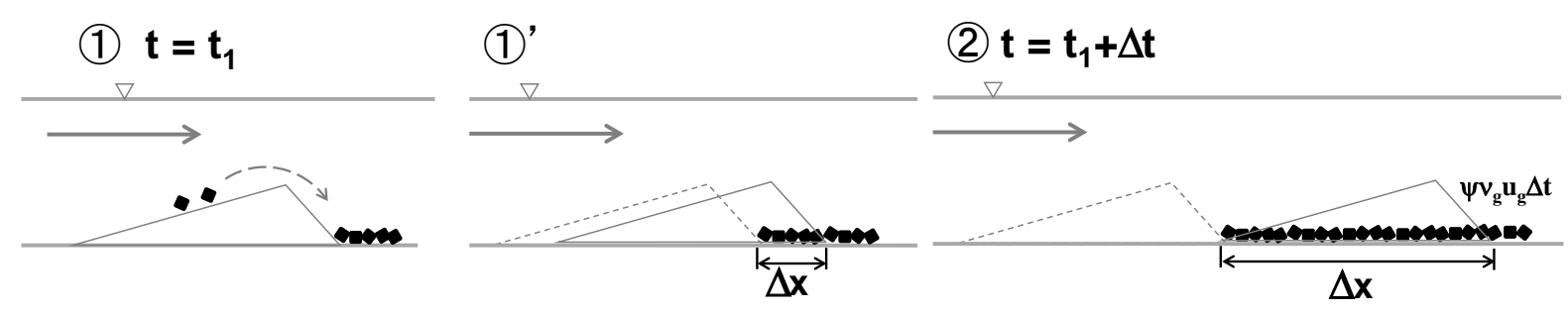

Figure 6. Concept of deposition process of CPOM with ripple.

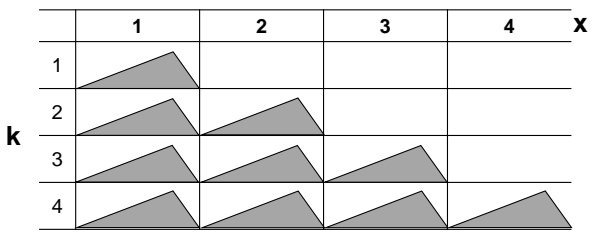

\begin{tabular}{|c|c|c|c|c|}
\hline & 1 & 2 & 3 & 4 \\
\hline 1 & $\psi$ & - & - & - \\
\hline 2 & $\begin{array}{l}\psi+\beta \psi \\
=\psi(1+\beta)\end{array}$ & $\begin{array}{l}\psi[(1-\psi)+(1-\beta) \psi] \\
=\psi(1-\psi \beta)\end{array}$ & - & - \\
\hline 3 & $\begin{array}{l}\psi+\beta(\psi+\beta \psi \\
=\psi\left(1+\beta+\beta^{2}\right)\end{array}$ & $\begin{array}{l}\psi[(1-\psi)+(1-\beta)(\psi+\beta \psi)] \\
=\psi\left(1-\psi \beta^{2}\right)\end{array}$ & $\psi\left[(1-\psi)^{2}+(1-\beta) * N_{22}\right]$ & - \\
\hline 4 & $\begin{array}{l}\psi+\beta(\psi+\beta(\psi+\beta \psi)) \\
=\psi\left(1+\beta+\beta^{2}+\beta^{3}\right)\end{array}$ & $\begin{array}{l}\psi\left[(1-\psi)+(1-\beta) * N_{31}\right] \\
=\psi\left(1-\psi \beta^{3}\right)\end{array}$ & $\psi\left[(1-\psi)^{2}+(1-\beta) * N_{32}\right]$ & $\psi\left[(1-\psi)^{3}+(1-\beta) * N_{33}\right]$ \\
\hline k & $\psi+\beta * N_{(k-1) 1}$ & $\psi\left[(1-\psi)+(1-\beta) * N_{(k-1)}\right]$ & $\psi\left[(1-\psi)^{2}+(1-\beta) * N_{(k-1-1) 2}\right]$ & $\psi\left[(1-\psi)^{\beta}+(1-\beta) * N_{\left.(k-1))_{3}\right]}\right]$ \\
\hline
\end{tabular}

Figure 7. Model concept of CPOM deposition process with ripple.

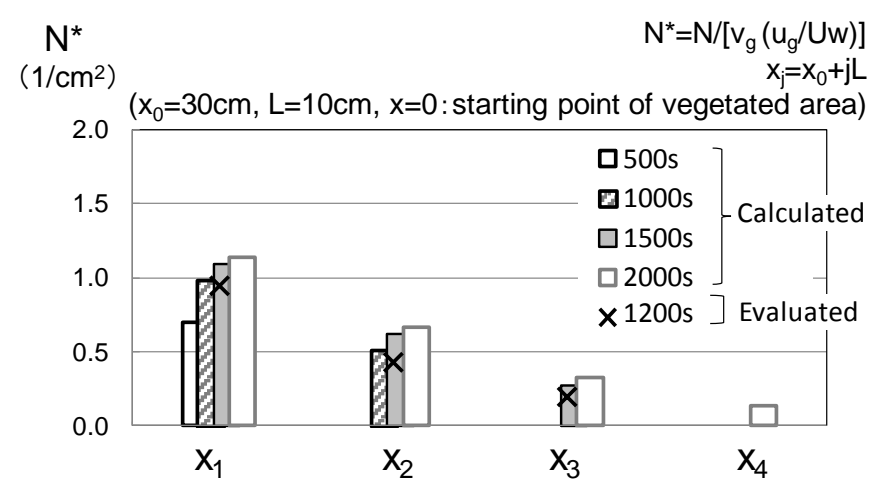

Figure 8. Comparison between calculated and evaluated results of CPOM deposition.

deposition amount at each point is increased with the development of ripples, and propagated to the downstream. These characteristics of CPOM deposition were represented well by our calculation as shown in Figure 8.

$X$ marks in the figure represent the evaluated CPOM deposition amount by using the measured experimental data of CPOM deposition amount at 1200 seconds after the flume experiment starts. They are evaluated by using the relationship between several factors of ripple migration and bed load transport rate based on the following equation $\left(N^{*}=N /\left[v_{\mathrm{g}}\left(u_{g} / U_{w}\right)\right]\right)$ and these each value of $U_{w}=0.02 \mathrm{~cm} / \mathrm{s}, u_{g}=5 \mathrm{~cm} / \mathrm{s}$ (estimated by Equation (2)) $v_{\mathrm{g}}=0.06 \mathrm{~cm}^{2}$ (calculated based on the supplied POM ratio and $u_{g}$ ), $N$ (measured CPOM deposition amount by flume experiment, see Table 2). The figure shows the comparison of the evaluated results at 1200 seconds with the calculated results with time progress. The calculated value agrees well with the evaluated value. Therefore, our conceptual model is effective to understand the general tendency of temporal and spatial change of CPOM deposition as shown in Figure 8.

\section{Conclusion}

In this study, our efforts have highlighted evaluation of POM deposition on sandbar which is characterized by vegetated area and fine sand deposition there. We investigated the deposition mechanisms of sediment and POM through a field observation and a laboratory experiment. After the basic deposition characteristics were extracted by the field observation, we observed the deposition mechanisms by the laboratory experiment. The conclusions of this study are summarized that ripples are formed by the bed load in the riparian vegetation. And CPOM is 
captured by trough of ripples formed by the wave action. The difference of the shear velocity in the vegetated and non-vegetated area is a key for the sediment transport of our study, and it is described by the boundary layer concept. Then, POM behavior with ripples is described by a conceptual model which will affect other aspects in ecosystem management based on fluvial processes.

\section{References}

[1] Vannote, R.L., Minshall, G.W., Cummins, K.W., Sedell, J.R. and Cushing, C.E (1980) The River Continuum Concept. Canadian Journal of Fishery and Aquatic Science, 37, 130-137. http://dx.doi.org/10.1139/f80-017

[2] Cummins, K.W. (1974) Structure and Function of Stream Ecosystems. BioScience, 24, 631-641. http://dx.doi.org/10.2307/1296676

[3] Obana, M., Uchida, T. and Tsujimoto, T. (2012) Deposition of Sand and Particulate Organic Matter in Riparian Vegetation. Advances in River Engineering, 18, 47-52 (in Japanese).

[4] Jeon, H.S., Obana, M. and Tsujimoto, T. (2014) Concept of Bed Roughness Boundary Layer and Its Application to Bed Load Transport in Flow with Non-Submerged Vegetation. Journal of Water Resource and Protection, 6, 881-887. http://dx.doi.org/10.4236/jwarp.2014.610082

[5] Yalin, M.S. (1977) Sediment Transport. 2nd Edition, Pergamon Press, New York, Chapter 7, 209-267.

[6] Ashida, K. and Michiue, M. (1972) Hydraulic Resistance of Flow in an Alluvia Bed and Bed Load Transport Rate. Proceedings of Japan Society of Civil Engineers, No. 206, 59-69 (in Japanese). 
Scientific Research Publishing (SCIRP) is one of the largest Open Access journal publishers. It is currently publishing more than 200 open access, online, peer-reviewed journals covering a wide range of academic disciplines. SCIRP serves the worldwide academic communities and contributes to the progress and application of science with its publication.

Other selected journals from SCIRP are listed as below. Submit your manuscript to us via either submit@scirp.org or Online Submission Portal.
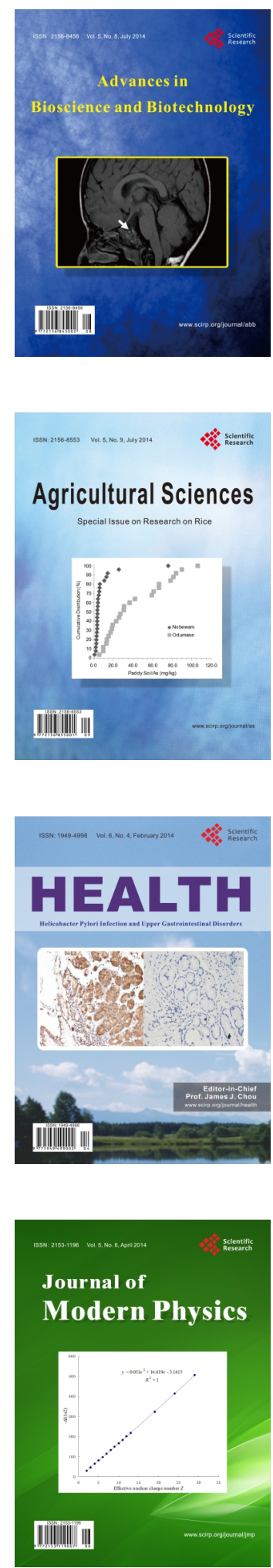
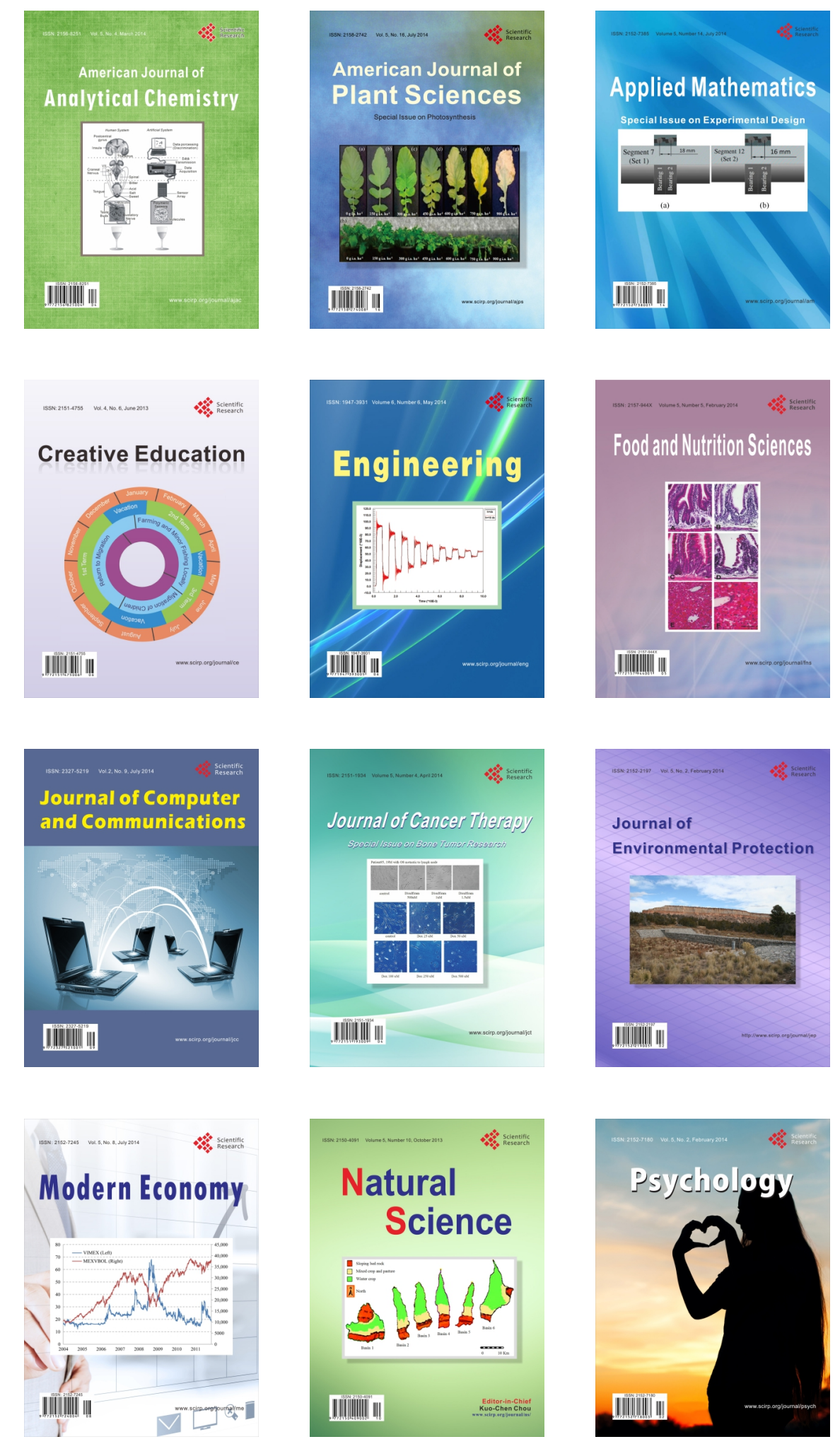